\title{
Microbiology of Tracheal Secretions: What to Expect with Children and Adolescents with Tracheostomies
}

\author{
Mikhael R. El Cheikh ${ }^{1}$ Juliane M. Barbosa ${ }^{1}$ Juliana A. S. Caixêta ${ }^{1}$ Melissa A. G. Avelino ${ }^{1,2}$ \\ 1 Otolaryngologist, Universidade Federal de Goiás, Goiânia, GO, Brazil \\ 2 Pontificia Universidade Católica de Goiás, Goiânia, GO, Brazil \\ Address for correspondence Juliana Alves de Sousa Caixêta, MD, \\ UniEvangélica - Av. Universitária Km. 3.5 - Cidade Universitária - \\ Anápolis - GO CEP: 75083-515, Brazil \\ Int Arch Otorhinolaryngol 2018;22:50-54. \\ (e-mail: jualves39@yahoo.com.br).
}

\begin{abstract}
Introduction People with tracheostomies exhibit a higher risk of colonization of the lower respiratory tract, acute tracheitis and pneumonia. Despite this, the culture of tracheal secretions is not a routine in most hospitals, and sometimes empiric therapy is based on personal experience, which is not an ideal situation.

Objective To recognize the pathogens present in the tracheal secretions collected from people up to 18 years old with tracheostomies.

Methods Prospective evaluation of patients under the age of 18 of a tertiary care hospital. A standardized questionnaire was completed, and tracheal secretion aspirates were sent for microbiological cultures and antibiograms.

Results Twenty patients under 18 years of age were evaluated, $65 \%$ of whom were male. The microbiological culture was positive in $90 \%$ of the patients, and the most common microorganisms found were Pseudomonas aeruginosa (55.5\%) and Staphylococcus aureus (27.7\%).

Discussion Tracheostomized children and adolescents have respiratory tracts colonized by pathogens, the most common of which is Pseudomonas aeruginosa. These

\section{Keywords}

- tracheostomy

- children

- adolescents

- infection

- bacteria

- tracheal aspirate patients must undergo tracheal secretion cultures, whether they present symptoms or not, to determine if there is a correlation between the colonization and the infections. This finding could guide the adequate treatment, avoiding the inappropriate use of antibiotics and indicating the better therapy in cases of laryngeal reconstruction. Conclusion In this sample, the culture of tracheal secretions was mainly positive, and the most common agent was $P$. aeruginosa. We suggest the routine access to Brazilian children and adolescents tracheal secretion cultures, which could help to make a profile of these children and guide the use of antibiotics.
\end{abstract}

\section{Introduction}

People with tracheostomies are under a greater risk of respiratory infections because the tracheostomy tube functions as a bypass that eliminates the protection provided by the nasal cavity. In addition to suppressing functions involving filtration, humidification, and warming of the air, the tracheostomy creates a direct entrance for viruses and bacteria into the lower respiratory tract. The presence of the tube also causes a local inflammatory reaction that increases the risk of infection. ${ }^{1}$ Some studies show that it is virtually impossible to keep the lower respiratory tract sterile in children; pathogens have been found to be present in up to $100 \%$ of children 2 weeks after surgery. ${ }^{2-4}$ It is received

August 2, 2016

accepted

January 29, 2017

published online

April 24, 2017
DOI https://doi.org/

$10.1055 / \mathrm{s}-0037-1601403$. ISSN $1809-9777$.
Copyright (e 2018 by Thieme Revinter

Publicações Ltda, Rio de Janeiro, Brazil
License terms

c) $(1) \$$ 
common for tracheostomized children to have their trachea colonized by bacteria. This colonization can increase the risk of infection, usually by the same agent present in their respiratory tracts. ${ }^{5,6}$ However, some authors suggest that lower respiratory tract infections in tracheostomized children do not occur because of colonizing bacteria, but because of exposure to other bacteria. ${ }^{7}$

Tracheal secretion cultures have been used to treat tracheostomized children with irritation in the lower respiratory tract, as well as to guide therapy with antibiotics after laryngotracheal surgery. $6,8,9$

Since the 1960's, the number of children hospitalized on mechanical ventilation in intensive care units has increased; with this increase, the need for tracheostomies in this age group has increased as well. ${ }^{10,11}$ This movement was accompanied by an increase in the number of surgeries for laryngotracheal reconstruction, particularly in the 1970's, because these children needed to be rehabilitated. ${ }^{12,13}$ One of the key points for the success of the procedure is the prevention and treatment of infection at the surgical site, since infection can lead to therapeutic failure, loss of the graft, bacterial superinfection and sepsis. In these cases, the sensible and guided use of antibiotics would be essential. $^{14-16}$

There is a lack of data on tracheal secretion cultures in tracheostomized children and adolescents in Brazil. As a result, the main pathogens responsible for colonizing and/ or infecting the patients' tracheae are not known. Some Brazilian hospitals may perform routine research on the microorganisms present in their patients' tracheae, but access to that data is limited, since published data are scarce. It is still impossible to know if the treatment for lower respiratory tract infections in these patients is handled empirically or if it is based on guidance from laboratory diagnosis. Considering these facts, the evaluation of the tracheal secretion cultures of children and adolescents from our hospital could provide information with immediate as well as future impacts on the care provided to these patients.

\section{Objective}

To evaluate the microbiology of tracheal secretion aspirates from tracheostomized patients under 18 years old treated in a tertiary referral hospital.

\section{Materials and Methods}

This is a cross-sectional prospective study. Tracheostomized patients up to 18 years of age treated in the Otorhinolaryngology department of our tertiary referral hospital between November 2014 and November 2015 were evaluated. All patients with tracheostomies of our ear, nose and throat department were invited to participate in the research. The study has been submitted on the Plataforma Brasil website, and has been approved by the institution's ethics committee (CAAE Registry No.: 046819/2014). The patients' guardians and the children themselves were invited to participate in this study, which was developed after they signed the informed consent form.

Tracheal secretions were collected using sterile gloves and by aspirating the patients using an aspiration tracheal probe recommended for the size of the tracheostomy tube. Once the tracheal secretion filled the probe completely, a sterile syringe containing $2 \mathrm{~mL}$ of saline solution was attached to the probe, and the content was injected until all of the content in the probe had been collected in a sterile vial appropriate for microbiological cultures.

The specimens were seeded in blood agar, chocolate agar and MacConkey agar (BD, Franklin Lakes, NJ, US) using the standard technique. ${ }^{4,6}$ The plaques were incubated in 5-7\% $\mathrm{CO}_{2}$ at temperatures between $35^{\circ} \mathrm{C}$ and $37^{\circ} \mathrm{C}$ for 48 hours. Bacterial growth was quantified as the amount of colony forming units per $\mathrm{mL}(\mathrm{CFU} / \mathrm{mL})$. All microorganisms identified were reported. Counts of over $10^{6} \mathrm{CFU} / \mathrm{mL}$ were considered positive. $4,6,8,16$

All children underwent laryngeal evaluations using a flexible nasal fiberscope, as well as rigid laryngeal endoscopies using $0^{\circ}, 30^{\circ}$, and $70^{\circ}$ endoscopes to diagnose laryngotracheal pathologies.

The data collected were organized in an Excel $^{\circledR}$ (Microsoft, Redmond, WA, US) spreadsheet for analysis in the Statistical Package for the Social Sciences (IBM SPSS ${ }^{\circledR}$, Chicago, IL, US) software, version 20.0. All means are presented with standard deviation (SD) values. Descriptive statistics, such as percentages, were used to describe the cultured microorganisms in the full cohort of study subjects. Fisher's exact test was used to determine if there was a nonrandom association between the categorical variables. A value of $p<0.05$ was considered statistically significant for all analyses.

\section{Results}

A total of 20 children under 18 years of age $(7.5 \pm 5$ years $)$ were evaluated, 13 (65\%) of whom were male. The average age at the time of the tracheostomy was $2.8 \pm 3.6$ years of age. About half the procedures were made by the emergency care team, meaning the patient presented severe respiratory distress without the possibility of endotracheal intubation. The data are presented in - Table $\mathbf{1}$.

The most common disease found in the endoscopic evaluation of the respiratory tract was acquired subglottic stenosis, followed by neoplasia, including recurring laryngeal papillomatosis and one case of giant cervical

Table 1 General data on the patients who participated in the study

\begin{tabular}{|l|l|}
\hline $\begin{array}{l}\text { Clinical and epidemiological } \\
\text { characteristics }\end{array}$ & \\
\hline Age (years) & $7.5 \pm 5$ \\
\hline Male gender & $13(65 \%)$ \\
\hline $\begin{array}{l}\text { Age when tracheostomy was } \\
\text { performed (years) }\end{array}$ & $2.8 \pm 3.66$ \\
\hline Urgent tracheostomy & $9(45.0 \%)$ \\
\hline
\end{tabular}


52 Microbiology of Tracheal Secretions in Children El Cheikh et al.

Table 2 Causes of obstruction of the upper respiratory tract

\begin{tabular}{|l|l|}
\hline & $\mathbf{n}(\%)$ \\
\hline Acquired glottic stenosis & $12(60 \%)$ \\
\hline Laryngeal neoplasia & $3(15 \%)$ \\
\hline Tracheal stenosis & $2(10 \%)$ \\
\hline Vocal cord immobility & $1(5 \%)$ \\
\hline Craniofacial alterations & $1(5 \%)$ \\
\hline Laryngeal membrane & $1(5 \%)$ \\
\hline
\end{tabular}

lymphangioma with laryngeal and tracheal extensions, as shown in - Table 2.

Among the children analyzed, 45\% exhibited some sort of comorbidity, and $40 \%$ had been born premature. Prematurity was found to have a statistically significant association with the presence of comorbidities $(p=0.002)$. The most common comorbidities were pneumopathies, followed by neuropathies, as shown in - Table 3. Two children had respiratory distress syndrome, two had bronchopulmonary dysplasia, and one had Lung-Kidney disease. Of the patients with neuropathy, all of them $(n=2)$ had cerebral palsy.

Only $10 \%$ of the patients had negative tracheal secretion cultures, and, in patients with positive cultures, the most prevalent microorganism was Pseudomonas aeruginosa, followed by Staphylococcus aureus (-Table 4). Among the children with positive cultures for $P$. aeruginosa, six (60\%) had been born premature; among the children carried to term, only $30 \%$ were colonized by the same microorganism. Two patients (10\%) had positive cultures for more than one microorganism. There was no statistically significant correlation between the pathogen identified and age, gender, prematurity, or urgency of the procedure.

\section{Discussion}

Most of the evaluated children were male, as found in other studies. $^{4,17,18}$

This study confirms previous findings that most tracheostomized children experience tracheal colonization by potentially pathogenic bacteria, similar to what occurs in patients with chronic obstructive pulmonary disease and cystic

Table 3 Comorbidity found among patients with tracheostomies

\begin{tabular}{|l|l|}
\hline Comorbidity & $\mathbf{n}(\%)$ \\
\hline Pneumopathy & $6(30 \%)$ \\
\hline Neuropathy & $2(10 \%)$ \\
\hline Genetic syndrome & $2(10 \%)$ \\
\hline Cardiopathy & $1(5 \%)$ \\
\hline $\begin{array}{l}\text { Alterations in the } \\
\text { gastrointestinal tract }\end{array}$ & $1(5 \%)$ \\
\hline
\end{tabular}

Table 4 Frequency of microorganisms found in tracheal secretions and antibiotics used to counter them

\begin{tabular}{|c|c|c|}
\hline Microorganism & n (\%) & Sensitivity (\%) \\
\hline Staphylococcus aureus & $5(25 \%)$ & \\
\hline Benzylpenicillin & & 0 \\
\hline $\begin{array}{l}\text { Sulfamethoxazole / } \\
\text { Trimethoprim }\end{array}$ & & $40 \%$ \\
\hline Vancomycin & & $100 \%$ \\
\hline Tetracycline & & $100 \%$ \\
\hline Clindamicyn & & $40 \%$ \\
\hline Oxacylin & & $100 \%$ \\
\hline Erytromycin & & $40 \%$ \\
\hline $\begin{array}{l}\text { Pseudomonas } \\
\text { aeruginosa }\end{array}$ & $10(50 \%)$ & \\
\hline Imipenem & & $90 \%$ \\
\hline Amycacin & & $80 \%$ \\
\hline Aztreonan & & $80 \%$ \\
\hline Ciproflaxacin & & $80 \%$ \\
\hline Gentamicin & & $80 \%$ \\
\hline Levofloxacin & & $80 \%$ \\
\hline Meropenem & & $90 \%$ \\
\hline Ceftazidime & & $90 \%$ \\
\hline Morganella morganii & $2(10 \%)$ & \\
\hline Amicacin & & $100 \%$ \\
\hline Ceftazidime & & $100 \%$ \\
\hline $\begin{array}{l}\text { Amoxicilin }+ \\
\text { clavulanate }\end{array}$ & & 0 \\
\hline Ceftriaxone & & $100 \%$ \\
\hline Levofloxacin & & $100 \%$ \\
\hline Meropenen & & $100 \%$ \\
\hline Klebsiella pneumoniae & $1(5 \%)$ & \\
\hline Cefepime & & $100 \%$ \\
\hline Ceftazidime & & $100 \%$ \\
\hline Ciprofloxacin & & $100 \%$ \\
\hline Amicacyn & & $100 \%$ \\
\hline Imipenem & & $100 \%$ \\
\hline Gentamicin & & $100 \%$ \\
\hline Ampicilin & & 0 \\
\hline Stentotrophomonas sp. & $1(5 \%)$ & \\
\hline Cefepime & & $100 \%$ \\
\hline Ceftazidime & & $100 \%$ \\
\hline Ciprofloxacin & & $100 \%$ \\
\hline Amicacyn & & $100 \%$ \\
\hline Imipenem & & $100 \%$ \\
\hline Gentamicin & & $100 \%$ \\
\hline $\begin{array}{l}\text { Sulfametoxazol + } \\
\text { trimetropim }\end{array}$ & & 0 \\
\hline
\end{tabular}


Table 4 (Continued)

\begin{tabular}{|l|l|l|}
\hline Microorganism & $\mathbf{n}(\%)$ & Sensitivity (\%) \\
\hline Proteus mirabilis & $1(5.5 \%)$ & \\
\hline Amicacin & & $100 \%$ \\
\hline $\begin{array}{l}\text { Amoxicilin }+ \\
\text { clavulanate }\end{array}$ & & $100 \%$ \\
\hline Ampicilin & & $100 \%$ \\
\hline Cefepime & & $100 \%$ \\
\hline Ceftriaxon & & $100 \%$ \\
\hline Gentamicyn & & $100 \%$ \\
\hline
\end{tabular}

fibrosis. ${ }^{1,6,9,19}$ The most frequent microorganisms found in the literature were $P$. aeruginosa and S. aureus.

None of our cultures were positive for methicillin-resistant Staphylococcus aureus (MRSA), which differs from the literature, ${ }^{4,7,18}$ and that suggests that MRSA grows in countries where the use of antibiotics has grown and in children with tracheostomies in place for more than 5 years. ${ }^{18}$ Thus, when a patient with a tracheostomy presents with signs and symptoms of respiratory infection, suspicion of MRSA should be higher in those who have had a tracheostomy in place longer. Colonization by more than one type of bacteria is not uncommon in the literature, a finding which is consistent with the evidence found in our study. ${ }^{17-19}$ Although we included children with a great variability of age and pathologies, microorganisms similar to the ones found in other studies were found in our tracheal cultures. ${ }^{7,9,17,18}$

Tracheostomies increase the risk of infection by allowing the air to reach the respiratory tract without having been humidified, warmed, or filtered in the nasal cavity. In addition, the tube itself causes a local inflammatory reaction, and increases the susceptibility to colonization of the mucous membrane by several pathogens, thus increasing the predisposition to infection. ${ }^{1,8}$ It is also known that local hygiene is not always performed as recommended. Respiratory tract manipulation that occurs during the aspirations and tube changes cannot be underestimated. ${ }^{9,20}$ Several studies have established that subjects with long-term tracheostomies become chronically colonized with bacteria that may lead to serious illness and complications. ${ }^{2,8,21}$ However, there are no studies describing the relationship between the length of time with the tracheostomy and the spectrum of bacterial growth. Our sample is not enough to infer anything related to that.

Some studies suggest that routine tracheal secretion cultures can direct antibiotic therapy in cases of acute infections of the lower respiratory tract, similar to what occurs in patients with cystic fibrosis. ${ }^{2,16,21}$ However, some studies suggest that, although tracheal colonization is common, the microorganisms involved differ from those found in routine cultures, and that the change in potentially pathogenic bacteria occurs every two weeks among individuals outside a hospital environment. ${ }^{7,20}$ Nurture, the accuracy of the culture can be affected by the colonization of the upper respiratory tract, as well as by contamination of the instruments used in the procedure, factors that generate false positives in the results. ${ }^{22-24}$

In recent decades, improvements in upper respiratory tract surgery performed in the form of endoscopies as well as through external access have allowed for a growing number of children to be decannulated. Postoperative infections are known to decrease the success rate of surgeries, to lead to the loss of the graft, and to cause sepsis. ${ }^{25}$ Although the effects of bacterial colonization in the induction of tracheal subglottic stenosis are still uncertain, some studies suggest these factors may be related. ${ }^{14,26,27}$ The knowledge of which pathogens are present can direct preventive health care and prevent infection while avoiding the use of antibiotics of an inadequate spectrum.

A careful evaluation of the literature shows that, although colonization of the respiratory tract in tracheostomized children is certain, there are still many doubts involved in this situation. Are potentially pathogenic bacteria responsible for exacerbating upper respiratory tract infections? What is the influence of potentially pathogenic bacteria on the occurrence of tracheal and laryngeal stenosis? Can potentially pathogenic bacteria decrease the success rate of laryngeal and tracheal reconstruction? Can potentially pathogenic bacteria be countered? If so, how can it be accomplished?

Studies are scarce, discordant, present low levels of evidence, low numbers of patients, and are mainly retrospective. . $^{2,8,20,21,28}$

Our study presents several limitations. The sample size prevents adequate statistical analysis and a generalization of the results found. Because the patient sample is incongruous, the results cannot be adjusted by other factors, such as the amount of time between the tracheostomy and the collection of the material, the presence of comorbidities, and the presence of hospital environment pathogens. This information is limited because some patients were admitted to the hospital at the time of the exam. Anaerobic bacteria cultures were not performed because of the hospital's limited infrastructure. This study, however, is one of the few prospective studies involving children and adolescents, and is the only one published in indexed databases in Brazil. Studies with a higher number of patients, with systematic logging of aggravating conditions, and with laboratory exam results from children with tracheostomies must be performed in order to improve the care provided to these patients.

\section{Conclusion}

This study found that positive bacterial cultures are common in children and adolescents with tracheostomies, especially cultures of $P$. aeruginosa and $S$. aureus. The sample size prevents adequate statistical analysis and a generalization of the results found. We suggest that the routine access to tracheal secretions of people with tracheostomy cultures would help make a microbiological profile and guide the use of antibiotics. 
Note

The authors have conflict of interests to declare.

This study was not sent to be published elsewhere. Authors Mikhael R. El Cheikh and Juliane M. Barbosa were responsible for the initial review of the literature, the active search for patients, and the collections of the materials for the bacterial cultures. They also collected all data for the study. Author Juliana A. S. Caixêta was responsible for analyzing the data after it had been compiled; she performed the statistical analyses and wrote the study's discussion. Author Melissa A. G. Avelino was the creator of the project and supervised all of its stages, from the development to the revision of the final article. She was also responsible for submitting the project for grants from research funding institutions.

This study was performed with funds from the Fundação de Amparo à Pesquisa do Estado de Goiás (FAPEG).

\section{References}

1 Friedberg SA, Griffith TE, Hass GM. Histologic changes in the trachea following tracheostomy. Ann Otol Rhinol Laryngol 1965; 74(03):785-798

2 Brook I. Bacterial colonization, tracheobronchitis, and pneumonia following tracheostomy and long-term intubation in pediatric patients. Chest 1979;76(04):420-424

3 Morar P, Singh V, Jones AS, Hughes J, van Saene R. Impact of tracheotomy on colonization and infection of lower airways in children requiring long-term ventilation: a prospective observational cohort study. Chest 1998;113(01):77-85

4 Afolabi-Brown O, Marcus M, Speciale P, Pagala M, Kazachkov M. Bronchoscopic and nonbronchoscopic methods of airway culturing in tracheostomized children. Respir Care 2014;59(04): 582-587

5 Starner TD, Zhang N, Kim G, Apicella MA, McCray PB Jr. Haemophilus influenzae forms biofilms on airway epithelia: implications in cystic fibrosis. Am J Respir Crit Care Med 2006;174(02): 213-220

6 Sethi S, Evans N, Grant BJB, Murphy TF. New strains of bacteria and exacerbations of chronic obstructive pulmonary disease. $\mathrm{N}$ Engl J Med 2002;347(07):465-471

7 Cline JM, Woods CR, Ervin SE, Rubin BK, Kirse DJ. Surveillance tracheal aspirate cultures do not reliably predict bacteria cultured at the time of an acute respiratory infection in children with tracheostomy tubes. Chest 2012;141(03):625-631

8 Niederman MS, Ferranti RD, Zeigler A, Merrill WW, Reynolds HY. Respiratory infection complicating long-term tracheostomy. The implication of persistent gram-negative tracheobronchial colonization. Chest 1984;85(01):39-44

9 Solomon DH, Wobb J, Buttaro BA, Truant A, Soliman AM. Characterization of bacterial biofilms on tracheostomy tubes. Laryngoscope 2009;119(08):1633-1638

10 Allen MS. Surgical anatomy of the trachea. Chest Surg Clin N Am 2003;13(02):191-199, v
11 Lee W, Koltai P, Harrison AM, et al. Indications for tracheotomy in the pediatric intensive care unit population: a pilot study. Arch Otolaryngol Head Neck Surg 2002;128(11):1249-1252

12 Fearon B, Cotton R. Surgical correction of subglottic stenosis of the larynx. Prelimenary report of an experimental surgical technique. Ann Otol Rhinol Laryngol 1972;81(04):508-513

13 Hein EA, Rutter MJ. New perspectives in pediatric airway reconstruction. Int Anesthesiol Clin 2006;44(01):51-64

14 Nouraei SA, Petrou MA, Randhawa PS, Singh A, Howard DJ, Sandhu GS. Bacterial colonization of airway stents: a promoter of granulation tissue formation following laryngotracheal reconstruction. Arch Otolaryngol Head Neck Surg 2006;132(10):1086-1090

15 Polubothu S, Harrison S, Clement A, Kubba H. An audit of prophylactic antibiotic use in laryngeal reconstruction surgery. Int J Pediatr Otorhinolaryngol 2009;73(08):1157-1159

16 Brook I. Role of anaerobic bacteria in infections following tracheostomy, intubation, or the use of ventilatory tubes in children. Ann Otol Rhinol Laryngol 2004;113(10):830-834

17 Pozzi M, Galbiati S, Locatelli F, et al. Prevention of respiratory infections in tracheostomized patients of a pediatric long-term rehabilitation setting. Am J Infect Control 2015;43(04):394-396

18 McCaleb R, Warren RH, Willis D, Maples HD, Bai S, O’Brien CE. Description of Respiratory Microbiology of Children With LongTerm Tracheostomies. Respir Care 2016;61(04):447-452

19 Nobre S, Roda J, Félix M, Estêvão MH. Traqueostomia em idade pediátrica - experiência de um quarto de século. Acta Pediatr Port 2011;42(06):269-273

20 Bartlett JG, Faling LJ, Willey S. Quantitative tracheal bacteriologic and cytologic studies in patients with long-term tracheostomies. Chest 1978;74(06):635-639

21 Morar P, Singh V, Makura Z, et al. Oropharyngeal carriage and lower airway colonisation/infection in 45 tracheotomised children. Thorax 2002;57(12):1015-1020

22 Sachdev A, Chugh K, Sethi M, Gupta D, Wattal C, Menon G. Diagnosis of ventilator-associated pneumonia in children in resource-limited setting: a comparative study of bronchoscopic and nonbronchoscopic methods. Pediatr Crit Care Med 2010; 11(02):258-266

23 Wimberley N, Faling LJ, Bartlett JG. A fiberoptic bronchoscopy technique to obtain uncontaminated lower airway secretions for bacterial culture. Am Rev Respir Dis 1979;119(03):337-343

24 Meduri GU, Beals DH, Maijub AG, Baselski V. Protected bronchoalveolar lavage. A new bronchoscopic technique to retrieve uncontaminated distal airway secretions. Am Rev Respir Dis 1991;143(4 Pt 1):855-864

25 Monnier P. Pediatric Airway Surgery: Management of Laryngotracheal Stenosis in Infants and Children. New York, NY: Springer; 2011

26 Matt BH, Myer CM III, Harrison CJ, Reising SF, Cotton RT. Tracheal granulation tissue. A study of bacteriology. Arch Otolaryngol Head Neck Surg 1991;117(05):538-541

27 Reechaipichitkul W, Wongratanacheewin S, Ratanaanekchai T, Suetrong S, Nonthapa S. Bacteriology of granulation tissue in laryngotracheal stenosis patients. J Med Assoc Thai 2006;89(09): 1487-1490

28 Dal Nogare AR, Toews GB, Pierce AK. Increased salivary elastase precedes gram-negative bacillary colonization in postoperative patients. Am Rev Respir Dis 1987;135(03):671-675 